\title{
Organic carbon deposition and its control on iron sulfide formation of the southern East China Sea continental shelf sediments
}

\author{
Saulwood Lin*, Kuo-Ming Huang, Shin-Kuan Chen
}

Institute of Oceanography, National Taiwan University, \# 1, Roosevelt Rd., Sect. 4, Taipei, Taiwan

\begin{abstract}
Sulfate reduction rates and sedimentation rates were determined in sediments at ten stations on the southern East China Sea continental shelf. The area is characterized by relatively low organic carbon concentration with fast sedimentation rate. Rapid sulfate reduction rates, ranging from 1 to $4 \mathrm{mmol} / \mathrm{m}^{2} /$ day, were observed. Organic carbon concentration varied from 0.3 to $0.6 \mathrm{wt} \%$. Sedimentation rate varied from 0.2 to $0.7 \mathrm{~cm} / \mathrm{yr}$. In addition, normal marine $\mathrm{S} / \mathrm{C}$ ratios were observed. Up to $96 \%$ of pyrite-sulfur was reoxidized before its final burial. Sulfate reduction rate and pyrite-sulfur burial rate increased linearly with increasing organic carbon burial rate, indicating that organic carbon deposition controlled pyrite formation in the East China Sea continental shelf sediments. The organic carbon utilized by the sulfate reduction and its burial represented a significant but relatively small fraction of the primary production in the studied East China Sea region. (C) 2000 Elsevier Science Ltd. All rights reserved.
\end{abstract}

Keywords: Sulfate reduction; Pyrite; Iron sulfide; Organic carbon; Continental shelf; The East China Sea

\section{Introduction}

Quantitative determinations of organic carbon deposition and oxidation rate are important in understanding the fate of organic carbon in marine environment. Anoxic sulfate reduction and permanent burial are two primary pathways that determine the fate of sedimentary organic carbon in shelf sediments (Berner, 1982). Sulfate reduction can account for greater than $50 \%$ of the total organic carbon oxidized in shelf sediments whereas oxic respiration predominates in deep sea sediments with low

\footnotetext{
* Corresponding author.
} 
sedimentation rates (Canfield et al., 1993; Canfield, 1989; Jorgensen, 1982; Reimers et al., 1992; Henrichs and Reeburgh, 1987; Bender and Heggie, 1984; Reeburgh, 1983).

Organic carbon is oxidized during the sulfate reduction process:

$$
2 \mathrm{CH}_{2} \mathrm{O}+\mathrm{SO}_{4}^{2-} \Rightarrow \mathrm{H}_{2} \mathrm{~S}+2 \mathrm{HCO}_{3}^{-} .
$$

Consequently, sulfate reduction depends on the availability of organic carbon. A strong correlation between organic carbon and pyrite-sulfur has been observed, and has been used as an evidence of organic carbon limitation for pyrite formation (Berner, 1970, 1982; Goldhaber and Kaplan, 1974; Raiswell and Berner, 1985). The importance of organic carbon was further demonstrated by Westrich and Berner (1984), who demonstrated that sulfate reduction rate is ultimately dependent on the quantity and quality of organic carbon undergoing mineralization. As a result, organic carbon is a primary controlling factor for pyrite formation in the normal marine sediments.

Organic carbon deposited in shelf sediments constitutes a major sink for organic carbon removal from the ocean. Approximately $80 \%$ of organic carbon produced were deposited in shelf sediments alone (Berner, 1982). Recent studies indicated that organic carbon as well as inorganic particles were exported away from the East China Sea shelf system (Lin et al., 1992; Narita et al., 1990). If, in fact, a major portion of organic carbon were transported away from the shelf, less organic carbon would be available for the subsequent sedimentary mineralization processes. Thus sulfate reduction and pyrite formation may be limited by the lack of organic carbon supply.

Despite the fact that East China Sea is a major marginal sea and that a large portion of organic carbon may be deposited and utilized in the continental shelf sediment, little information is available regarding the organic carbon mineralization in this region. In particular, sulfate reduction is one of the most important process in oxidizing organic carbon in the shelf sediment. Hence, a study of sulfate reduction and pyrite formation in this region not only can provide information regarding carbon cycling but also a better understanding of the mechanism regarding pyrite formation on a regional scale. The purpose of this research, therefore, is to study the role of organic carbon deposition in controlling sulfate reduction and pyrite formation in the East China Sea continental shelf sediments.

\section{Sampling and methods}

Southern East China Sea continental shelf (Fig. 1) is characterized by a coastal fine-grained "mud-belt" with an organic carbon content of approximately $0.5 \%$, a relict coarse-grained quartz sand in the middle and outer shelf, and a region with high concentration of calcium carbonate content (more than $90 \%$ by weight) near the shelf edge (Lin and Chen, 1996; Huang and Lin, 1995; Lin et al., 1992; Niino and Emery, 1961). Both relict sand and carbonate shells were low in organic carbon, approximately $0.03 \%$ on average. Yangtze River is one of the major sources of sediment for the mud-belt since approximately $60 \%$ of the fine-grained sediments 


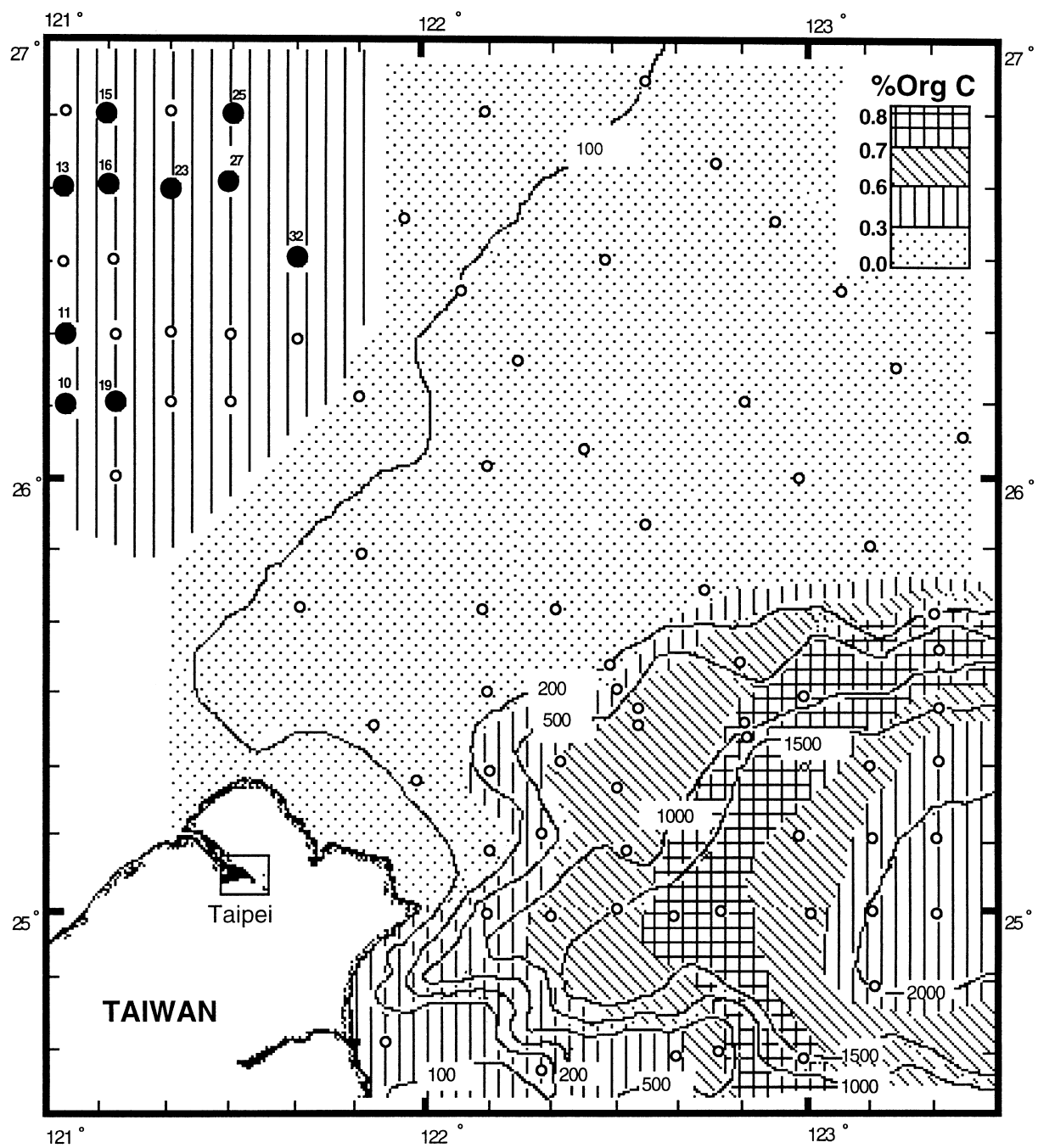

Fig. 1. Sampling locations and organic carbon concentrations of the study area. The symbols showing ranges of surface sediment organic carbon concentrations are on the upper right corner. Filled circles $(\mathbf{O})$ are stations where all measurements were performed. Open circles $(\bigcirc)$ are stations where only the surface sediment organic carbon concentration was measured. Depth contours are in meters.

from the Yangtze River were temperately deposited near the River mouth and later transported southward along the mud-belt (DeMaster et al., 1985; McKee et al., 1983).

Across shelf break, the organic carbon concentrations increased rapidly, showing a zonal distribution with the highest concentration in sediments at water depths of approximately 1000-1500 m (Lin et al., 1992). The organic carbon concentrations in the slope sediments were unusually high as compared to those in the East China Sea 
shelf sediments. A near bottom dense plume of suspended particle extending from shelf to slope has been observed. Extremely high 210-pb flux and sedimentation rates $(0.1-0.58 \mathrm{~cm} / \mathrm{yr})$ were observed in the slope area (Chung and Chang, 1995).

Primary productivity varied between 400 and $1900 \mathrm{mgC} / \mathrm{m}^{2} /$ day during the spring bloom and decreased to between 200 and $400 \mathrm{mgC} / \mathrm{m}^{2}$ /day in winter (Shiah et al., 1995; Guo, 1991). Diatoms were the predominant phytoplankton in the region (Chen, 1992).

\subsection{Sampling and handling}

Sediment core samples (Fig. 1) were collected with the Soutar type box core, and Benthos gravity core on board the R/V Ocean Researcher-I. Most samples were sectioned in $2 \mathrm{~cm}$ intervals in a nitrogen-filled glove bag (Aldrich) on board. Subsection samples were injected with $1-2 \mu \mathrm{Ci} \mathrm{Na}{ }_{2}^{35} \mathrm{SO}_{4}$ (NEN, DuPont) and incubated for $24 \mathrm{~h}$ at $22^{\circ} \mathrm{C}$ in the dark. After the incubation, samples were kept frozen in the refrigerator. A different subsample of the sediments was centrifuged $(4000 \mathrm{rpm}$, $15 \mathrm{~min}$ ) and filtered (Nuclepore, $0.45 \mu \mathrm{m}$ ) to obtain pore water. Pore water samples were stored in polyethylene (PE) vials at $4^{\circ} \mathrm{C}$ for the sulfate analysis. A fraction of wet sediments was used to determine the grain sizes. Part of the sediments were stored frozen in PE centrifuge tubes for drying on land. After being freeze-dried for one week using a Labconco Freeze-drier, sediments were ground to powder using an agate mortar and stored in polypropylene vials for organic carbon, ${ }^{210} \mathrm{~Pb}$ and iron determinations.

\subsection{Analyses}

Pore water sulfate concentration was determined by ion chromatography method of O'Dell et al. (1984) using a Dionex 4500i Ion Chromatography equipped with a conductivity detector and an IonPac AS4A anion exchange column. Samples were diluted 100 times and using $1.7 \mathrm{mM} \mathrm{NaHCO}$ and $1.8 \mathrm{mM} \mathrm{Na}_{2} \mathrm{CO}_{3}$ as the effluents with $0.025 \mathrm{~N} \mathrm{H}_{2} \mathrm{SO}_{4}$ as the regeneration fluid. The precision of sulfate analysis is $0.4 \%$ $(1 \sigma)$.

Organic carbon was determined with a LECO SC-444 carbon/sulfur analyzer. Approximately $0.25 \mathrm{~g}$ of dry sediment was pre-acidified with $\sim 2 \mathrm{ml}$ of $6 \mathrm{~N} \mathrm{HCl}$ to remove carbonate carbon. After drying on a hot-plate for $8 \mathrm{~h}$ at $\sim 60^{\circ} \mathrm{C}$, the sample was combusted $\left(1400^{\circ} \mathrm{C}\right)$ for the measurement of the sedimentary organic carbon content. The precision of the carbon analysis is $0.88 \%(1 \sigma)$ of the measured value using the LECO Carbon Standard (\%C: 1.04\%).

Pyrite-sulfur was determined using $\mathrm{Cr}(\mathrm{II})+6 \mathrm{~N} \mathrm{HCl}$ method and acid volatile sulfide was measured with cold $6 \mathrm{~N} \mathrm{HCl}$ extraction technique (Cornwell and Morse, 1987; Canfield et al., 1993). The precision was better than $1.5 \%(n=12)$ based on a sulfide standard $\left(\mathrm{Na}_{2} \mathrm{~S}\right.$, Sigma).

Grain sizes were determined by the pipette method of Folk (1968). Approximately $15 \mathrm{~g}$ of wet sediment were placed in the graduated cylinder, stirred and sampled sequentially. Variation of the triplicate analysis is less than $9 \%$. 
Sulfate reduction rate was measured using the ${ }^{35} \mathrm{SO}_{4}$ technique by Lin and Morse (1991) and Jorgensen (1982). Incubated sediments were distilled in an oxygen-free vessel for one hour to extract the reduced ${ }^{35} \mathrm{~S}$. The $\mathrm{H}_{2}{ }^{35} \mathrm{~S}$ evolved from boiling $\mathrm{Cr}$ (II) + acid distillation was carried to the $\mathrm{Zn}$-acetate $(0.28 \mathrm{M})$ trap with high purity nitrogen (99.9\%). Activity of $\mathrm{Zn}^{35} \mathrm{~S}$ and the remaining ${ }^{35} \mathrm{SO}_{4}$ were analyzed using a Liquid Scintillation Counter (Packard 1600TR).

Sedimentation rate was measured using the ${ }^{210} \mathrm{~Pb}$ method by alpha counting its daughter, ${ }^{210}$ Po (Flynn, 1968; Shokes, 1976; Nittrouer et al., 1979; Smith and Hamilton, 1984). A ${ }^{209}$ Po spike (Isotope Products Lab, CA) was added to approximately $5 \mathrm{~g}$ of dry sediment prior to leaching with concentrated $\mathrm{HNO}_{3}$. The extracted solution was filtered, dried and picked up in $\mathrm{HCl}$. After adjusting $\mathrm{pH}$, Po isotopes were plated on silver planchet (1", United Mineral, NY). Polonium activities were determined using EG and G Ortec silicon surface barrier detectors connected to a Seiko EG\&G Multichannel analyzer (7800). Counting errors were usually less than $5 \%$.

\section{Results}

\subsection{Organic carbon}

Organic carbon concentration of the surface sediments (Fig. 1) in the mud-belt varied within a narrow range of 0.3 to $0.6 \mathrm{wt} \%$ with an overall mean of $0.50 \pm 0.06 \%$ $(n=10)$. This average content is lower than those observed in the Amazon shelf and delta $(0.6 \pm 0.1 \%$, Aller et al., 1986), the Mississippi shelf and delta $(0.71 \pm 0.27 \%$, Lin and Morse, 1991), and the world shelf average (0.75\%, Berner, 1982). Very low concentrations of organic carbon (mean: $0.036 \% \pm 0.05 \%$, range: 0 to $0.31 \%, n=29$ ) were found in shelf sediments east of the mud-belt. The organic carbon content of the shelf sediment is rather low considering its average primary productivity of about $500 \mathrm{mgC} / \mathrm{m}^{2} /$ day for the shelf area and $130 \mathrm{mgC} / \mathrm{m}^{2} /$ day for the slope area (Shiah et al., 1995; Guo, 1991).

The organic carbon concentrations in the slope sediments (mean: $0.58 \% \pm 0.14 \%$, range: $0.2-0.8 \%, n=41$ ), on the other hand, were higher than those in the shelf sediments. A number of the lower values were found in sediments near the shelf break which may lower the calculated average concentration. The organic carbon displayed a zonal-type distribution in the slope sediments, increasing from a minimum at the shelf break to a maximum in sediments with overlying water depths of approximately 1000-1500 m, and later decreasing at greater depth.

The spatial variations of organic carbon in the surface sediments of the East China Sea continental shelf is related to the sediment grain sizes. Organic carbon concentrations (Fig. 2) increased with increasing fine-grained (diameters $<64 \mu \mathrm{m}$ ) sediments using data from this study and Lin and Chen (1996) which covered most of the East China Sea. Very little organic carbon was found in the middle and outer shelf sediments composed of coarse-grained quartz sand and carbonate shells, an indication of a lack of new organic carbon deposition. Niino and Emery (1961) also indicated that with the exception of inner shelf mud-belt, few modern sediments were 


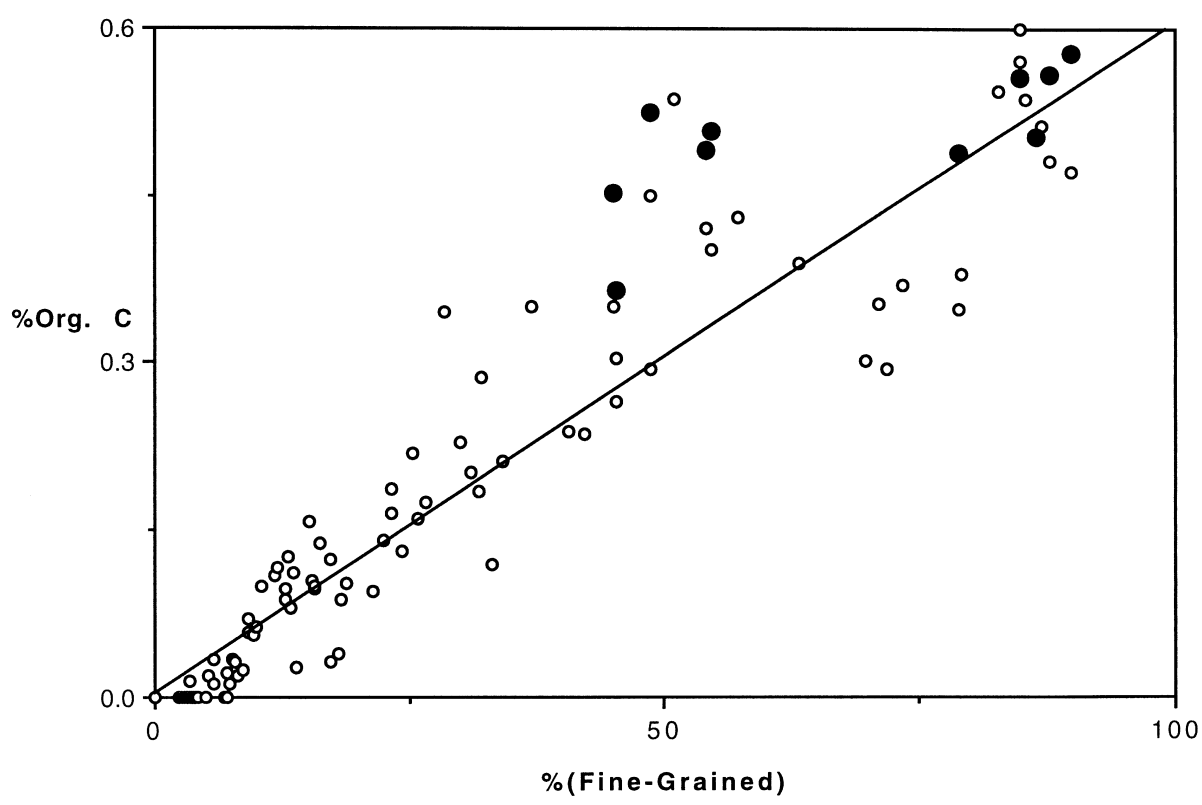

Fig. 2. Organic carbon increased linearly with increasing fine-grained sediments $\left(r^{2}=0.885\right)$. Open circles are surface sediments (97 stations, Lin and Chen, 1996) of the East China Sea continental shelf. Closed circles are surface sediments of the study region.

deposited on the East China Sea continental shelf. On the other hand, sediments from the inner shelf mud-belt in the study area are mostly fine-grained, with an average of $72.3 \pm 14.0 \%$ being silt and clay which contains relatively higher concentrations of organic carbon.

Vertically, organic carbon content decreased with increasing depth (Fig. 3). The highest concentration of organic carbon was often observed in the surface or near surface sediment. The extent of organic carbon depletion between the surface maximum and the subsurface minimum varies among sites, and a depletion of $10-30 \%$ as compared to those at depth was usually observed (e.g.: Station 27). An unusually rapid change in organic carbon concentration near the surface was found in station 32. Depletion of organic carbon was prominent in stations with relatively less organic carbon and more coarse-grained sediments $(10 \%<\%$ fine $<35 \%)$. In contrast, stations (Station 13,16) with greater than $90 \%$ fine-grained sediments showed only a slight depletion.

\subsection{Sedimentation rate}

The results of the total ${ }^{210} \mathrm{~Pb}$ measurements are plotted in Fig. 4. The distribution of ${ }^{210} \mathrm{~Pb}$ in the sediments can be described by

$$
\frac{\mathrm{d} A}{\mathrm{~d} t}=D \frac{\mathrm{d}^{2} A}{\mathrm{~d} Z^{2}}-\omega \frac{\mathrm{d} A}{\mathrm{~d} Z}-\lambda_{\mathrm{pb}} A=0,
$$




\section{\%Organic Carbon}
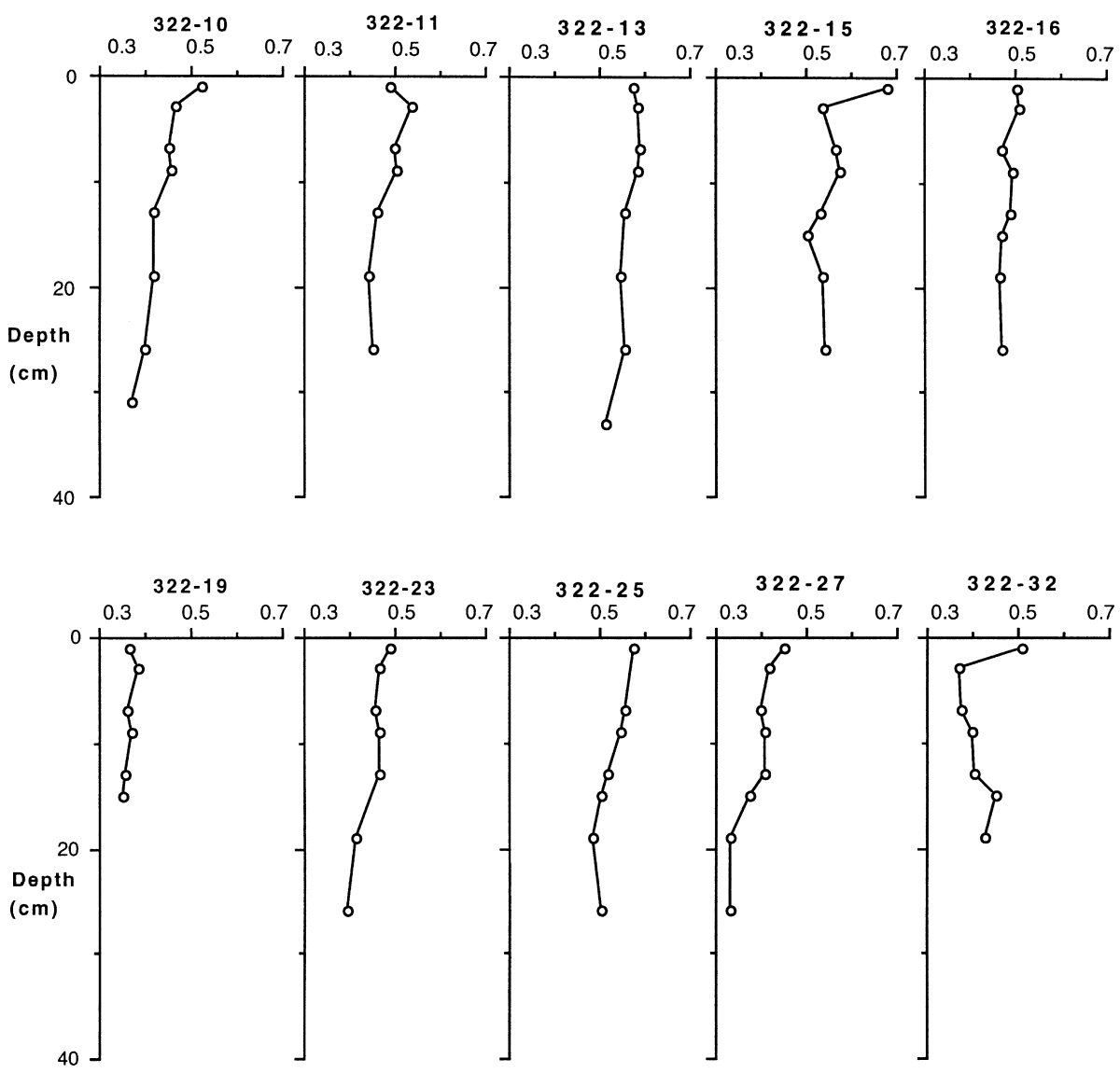

Fig. 3. Organic carbon concentration profiles.

where $A$ is the activity of ${ }^{210} \mathrm{~Pb}, t$ the time in year, $D$ the particle mixing coefficient, $\omega$ the sedimentation rate, and $\lambda_{\mathrm{Pb}}$ the decay constant of ${ }^{210} \mathrm{~Pb}$. Sedimentation rates were calculated from ${ }^{210} \mathrm{~Pb}$ distributions in sediments below the zone of mixing $(\sim 5 \mathrm{~cm})$ based on the sharp change of ${ }^{210} \mathrm{~Pb}$ gradient. If mixing is insignificant below this depth, then Eq. (2) reduces to

$$
-\omega \frac{\mathrm{d} A}{\mathrm{~d} Z}-\lambda_{\mathrm{pb}} A=0
$$

which has the solution of

$$
A(z)=A_{0} \exp [-(\lambda / \omega) z]
$$






Fig. 4. Excess ${ }^{210} \mathrm{~Pb}(\boldsymbol{\Phi})$, total ${ }^{210} \mathrm{~Pb}(\boldsymbol{\Phi})$, sedimentation rates and correlation coefficients of the study stations. $X$-axis error bars are the counting errors.

where $A(z)$ is the activity of ${ }^{210} \mathrm{~Pb}$ at depth $z$ and $A_{0}$ is the activity at the base of the mixed layer. The apparent sedimentation rates were calculated for each core by applying Eq. (4) to the log-linear portion of the excess ${ }^{210} \mathrm{~Pb}$ distributions (Fig. 4). These rates are upper limits as mixing will increase the apparent sedimentation rate above the true value.

The apparent sedimentation rates varied from 0.17 to $0.68 \mathrm{~cm} /$ year (Fig. 4). The supported ${ }^{210} \mathrm{~Pb}$ at depth were in a narrow range of $0.7-1.01 \mathrm{dpm} / \mathrm{g}$, similar to those measured by Chung and Chang (1995) near the study area. In stations $(13,16)$ with greater than $90 \%$ fine-grained sediments, however, relatively higher level of supported ${ }^{210} \mathrm{~Pb}, \sim 1.8 \mathrm{dpm} / \mathrm{g}$, were found. Surface mixing was observed mostly at the top $5 \mathrm{~cm}$ based on excess ${ }^{210} \mathrm{~Pb}$ profiles. Only data below the mixing zone were used in the sedimentation rate calculations. Carpenter et al. (1982) showed that mixing may cause 
${ }^{210} \mathrm{~Pb}$ derived sedimentation rate to be $2-3$ times higher than true sedimentation rate in the Washington slope sediments. DeMaster et al. (1985) indicated that mixing is important in the offshore East China Sea mud deposits where the major source of sediments was related to the Yellow River. However, they also demonstrated that rapid deposition and low mixing are the typical characteristics of the East China Sea inner shelf mud deposit. While the exact magnitude of mixing effect is not within the scope of this study, the apparent sedimentation rate based on the ${ }^{210} \mathrm{~Pb}$ measurements may likely represent a maximum sedimentation rate for the inner shelf mud sediments of this study.

Stations 15 and 25, located in the northern region of the study area, had the highest sedimentation rates of $0.6 \mathrm{~cm} / \mathrm{yr}$. The southern part of the study area, station 10 , had the lowest sedimentation rate of $0.17 \mathrm{~cm} / \mathrm{yr}$. Further south in the Taiwan Strait, sedimentation rates were in the range of $0.1-0.3 \mathrm{~cm} /$ year (Lin, unpublished data). The rate increased rapidly near the coastal area (Lee et al., 1993). North of the study area, typical sedimentation rate for the inner shelf sediments is $3 \mathrm{~cm} / \mathrm{yr}$ near the Yangtze River (DeMaster et al., 1985).

\subsection{Sulfate}

Pore water sulfate displayed a slightly vertical depletion (Fig. 5), with Station 15 showing the most perceptible sulfate depletion. The sulfate profiles resembled those observed in Amazon inner shelf mud (Aller et al., 1986). The absence of sulfate depletion was probably a combination result of bioirrigation and possibly sulfide reoxidation since little pyrite was accumulating in cores with high sulfate reduction rate in the top few centimeters.

\subsection{Sulfate reduction rate and pyrite}

Sulfate reduction rate increased with increasing depth (Fig. 6). A subsurface sulfate reduction rate maxima was always observed at a depth of approximately $5-15 \mathrm{~cm}$ with the exception of station 15 . The sulfate reduction rate maximum varied from 10 to $150 \mu \mathrm{M} /$ day. The depths where the peak occurred were usually beneath the bioturbated zone as indicated by the ${ }^{210} \mathrm{~Pb}$ profile (Fig. 4). Below the rate maximum, sulfate reduction rate decreased rapidly with increasing depth.

Integrated sulfate reduction rates varied from 1 to $6 \mathrm{mmol} / \mathrm{m}^{2} /$ day. All sulfate reductions were integrated to a depth of $20 \mathrm{~cm}$ for a consistent comparison. Sulfate reduction rates were considerably lower than those with high organic carbon contents (Chanton et al., 1987) and the Mississippi Delta (Lin and Morse, 1991) but similar to rates measured in the Maine shelf sediments (Christensen, 1989). An unusually high sulfate reduction rate was observed at station 32 , probably a result of a sharp change in the organic carbon concentration with depth (Fig. 3).

Pyrite concentration (Fig. 6) was relatively low in the upper $10 \mathrm{~cm}$ and gradually increased with increasing depth. The increase of pyrite with depth always appeared at or underneath the sulfate reduction rate maximum and continued to increase to the maximum depth sampled. The maximum pyrite concentration at depth in each 


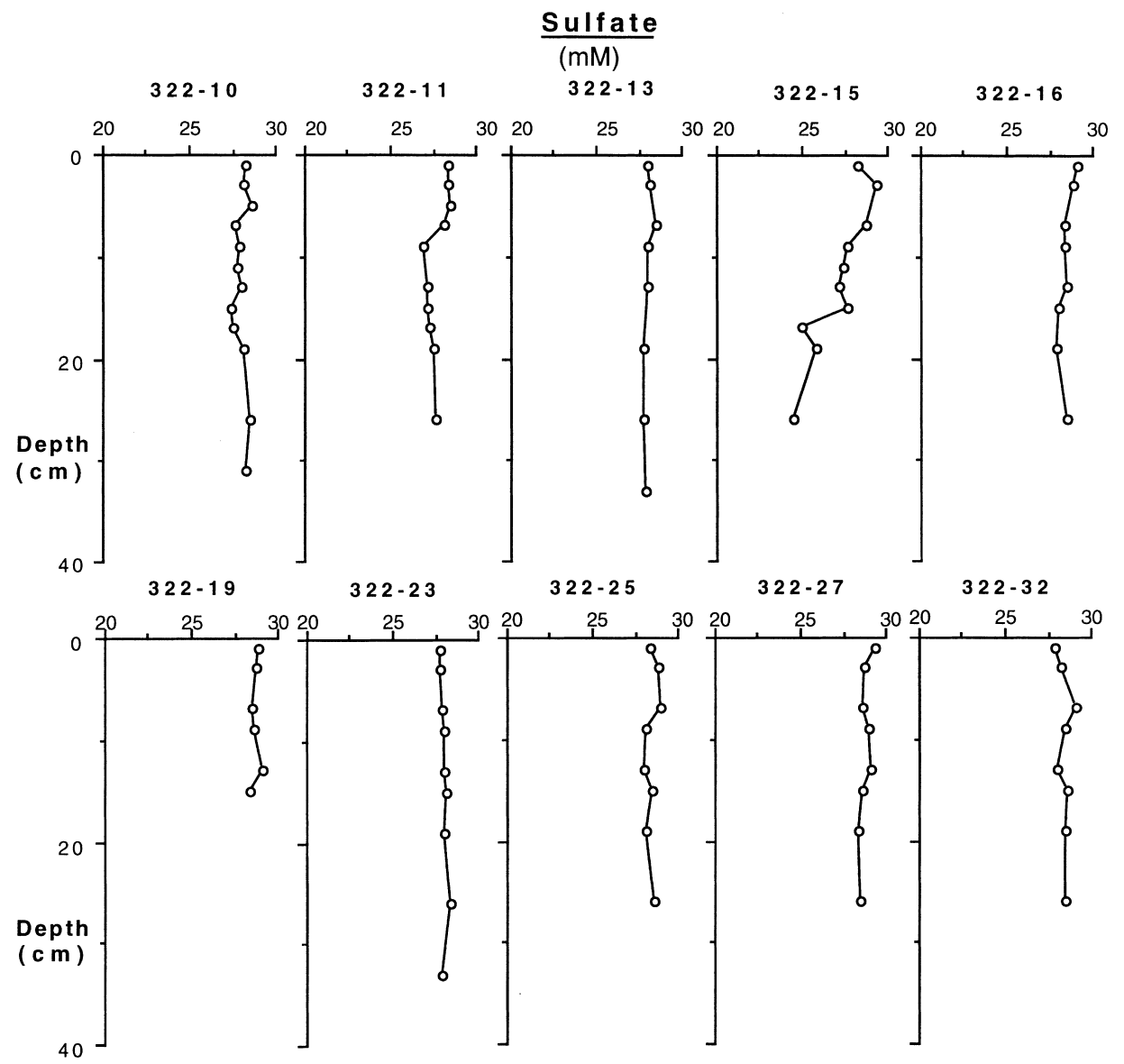

Fig. 5. Sulfate concentration profiles of the study stations.

station varied, mostly within $20-60 \mu \mathrm{mol} / \mathrm{g}$ in the study area. Pyrite concentration was in the range of $1-60 \mu \mathrm{mol} / \mathrm{g}$, slightly lower than those in the anoxic Gulf of Mexico sediments (Lin and Morse, 1991). Pyrite is the predominant sulfide mineral in the study region. The concentration of acid-volatile sulfide was very low $(<1 \mu \mathrm{mol} / \mathrm{g})$ and no dissolved sulfide was ever found throughout the study region.

\section{Discussion}

\subsection{Mathematical calculations}

The burial rates of carbon and pyrite are given by

$$
J_{z}=\rho(1-\phi) \omega[C]
$$




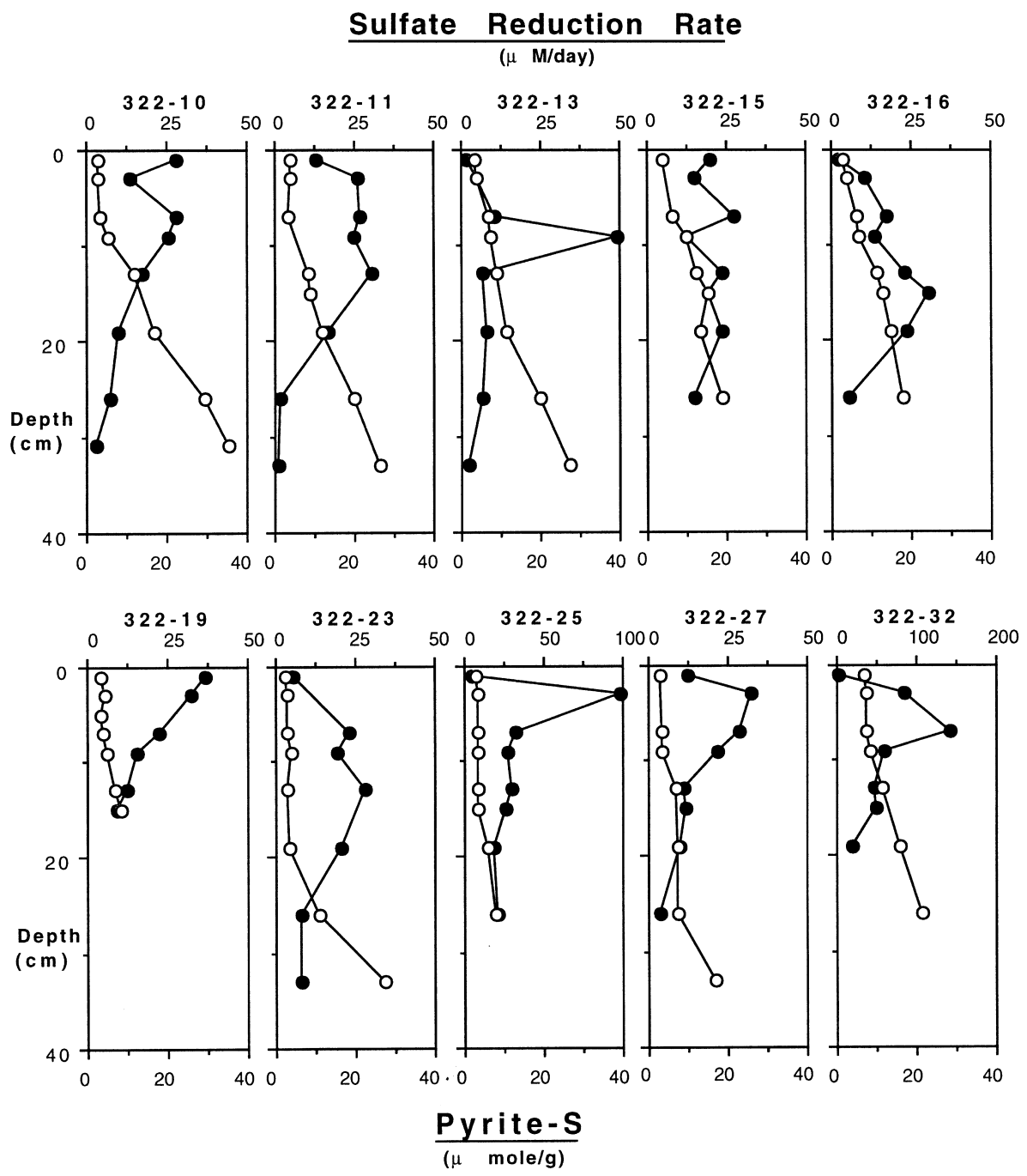

Fig. 6. Sulfate reduction rate $(\bigcirc)$ and pyrite-S concentration $(\bigcirc)$ profiles. Note the scale change for the stations 25 and 32.

in the absence of bioturbation and irrigation, where $J_{z}$ is flux of carbon $\left(C J_{z}\right)$ or pyrite $\left(S J_{z}\right)$ across a sediment horizon at a depth of $z(z=20 \mathrm{~cm}) ;[C]=$ organic carbon or pyrite concentration in the sediments at a depth of $z(20 \mathrm{~cm}$.); $\rho=$ dry bulk density $\left(\mathrm{g} / \mathrm{cm}^{3}=2.5\right) ; \phi=$ porosity; $\omega=$ sedimentation rate $(\mathrm{cm} / \mathrm{yr})$.

The fraction $(\%)$ of pyrite reoxidation is calculated by

$$
\operatorname{Fr}-S=S J_{z} / \mathrm{SRR}
$$


The fraction $(\%)$ of organic carbon utilized by the sulfate reduction and its final burial was calculated by

$$
\mathrm{Fr}-C=\left(2 \mathrm{SRR}+C J_{z}\right) / \mathrm{PP}
$$

assuming each mole of sulfate reduction required 2 mol of organic carbon according to Eq. (1). SRR is the integrated rate of sulfate reduction ( $\left.\mathrm{mmol} / \mathrm{m}^{2} / \mathrm{day}\right)$. $\mathrm{PP}$ is the average primary productivity in the water column $\left(500 \mathrm{mgC} / \mathrm{m}^{2} / \mathrm{day}\right)$.

Summarized in Table 1 are the organic carbon and pyrite burial rates, fractions of organic carbon utilized by sulfate reduction and burial, fractions of pyrite reoxidation, sedimentation rates and sulfate reduction rates for the study stations. Calculations of organic carbon and pyrite burial rates depended on sedimentation rates (Eq. (5)). Since the apparent sedimentation rate determined from the ${ }^{210} \mathrm{~Pb}$ method alone may overestimate the true sedimentation rates as indicated by DeMaster et al. (1985), both the organic carbon and pyrite burial rates may represent the maximum values.

\subsection{Organic carbon deposition and sulfate reduction}

Integrated sulfate reduction rates are linearly correlated with organic carbon burial ate in the East China Sea continental shelf sediments (Fig. 7). More labile organic material will be able to deliver to the sulfate reducer with higher sedimentation rate since the organic matter will undergo a shorter period of oxic and suboxic degradation. The observed linear correlation between organic carbon burial rate and sulfate reduction rate clearly demonstrated that higher rates of sulfate reduction depended on more organic carbon deposition. Consequently, sulfate reduction rates were controlled by the organic carbon burial. Similar conclusions were made by a number of studies (Henrichs, 1992; Lin and Morse, 1991; Canfield, 1991; 1989; Berner, 1978; Toth and Lerman, 1977) which showed that sulfate reduction rates correlated with sedimentation rates.

The combined organic carbon input to the sediment by sulfate reduction consumption and by organic carbon burial is $37.7 \mathrm{gC} / \mathrm{m}^{2} / \mathrm{yr}$ using an average sulfate reduction rate of $2.72 \pm 1.42$ and an organic carbon burial rate of $3.16 \pm 1.69 \mathrm{mmol} / \mathrm{m}^{2} / \mathrm{day}$ $(n=10$, Table 1$)$. This represents $20.6 \pm 10.4 \%$ (range: $13.2-41.3 \%$ ) of the primary production rate. A significant fraction of the annual productivity appears to have been missing and not depositing into the sediments. Though newly deposited sediments supplied fresh organic carbon to the sulfate reducer, the availability of organic carbon was limited in the East China Sea continental shelf. The sulfate reduction rate is proportional to a somewhat limited organic carbon burial rate. The relationship is such that at higher rates of organic carbon burial, more sulfate is reduced, resulting in the formation of more pyrite. The limited supply of organic carbon not only restrained the rate of sulfate reduction but also the final burial of pyrite in the East China Sea continental shelf sediments.

\subsection{Organic carbon control on pyrite formation}

Organic carbon burial is the major factor controlling iron sulfide mineral formation in the East China Sea continental shelf sediments. Pyrite-sulfur burial rates and sulfate 


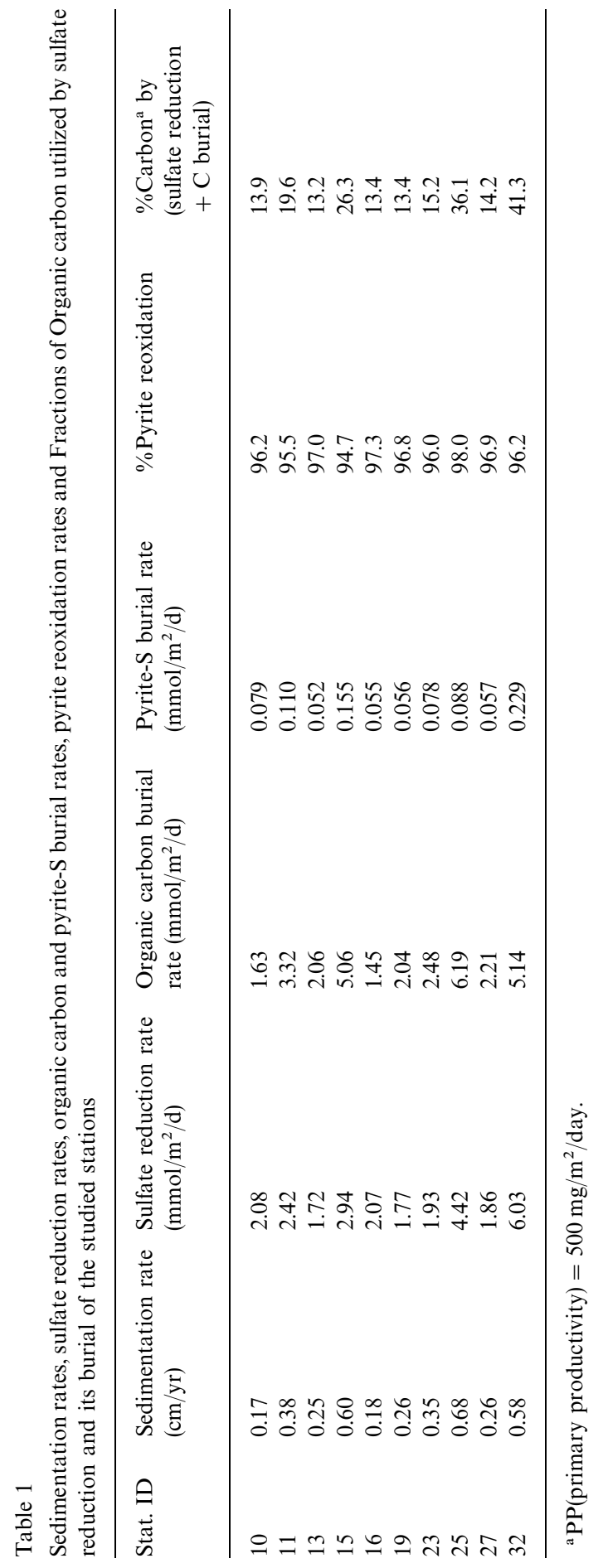




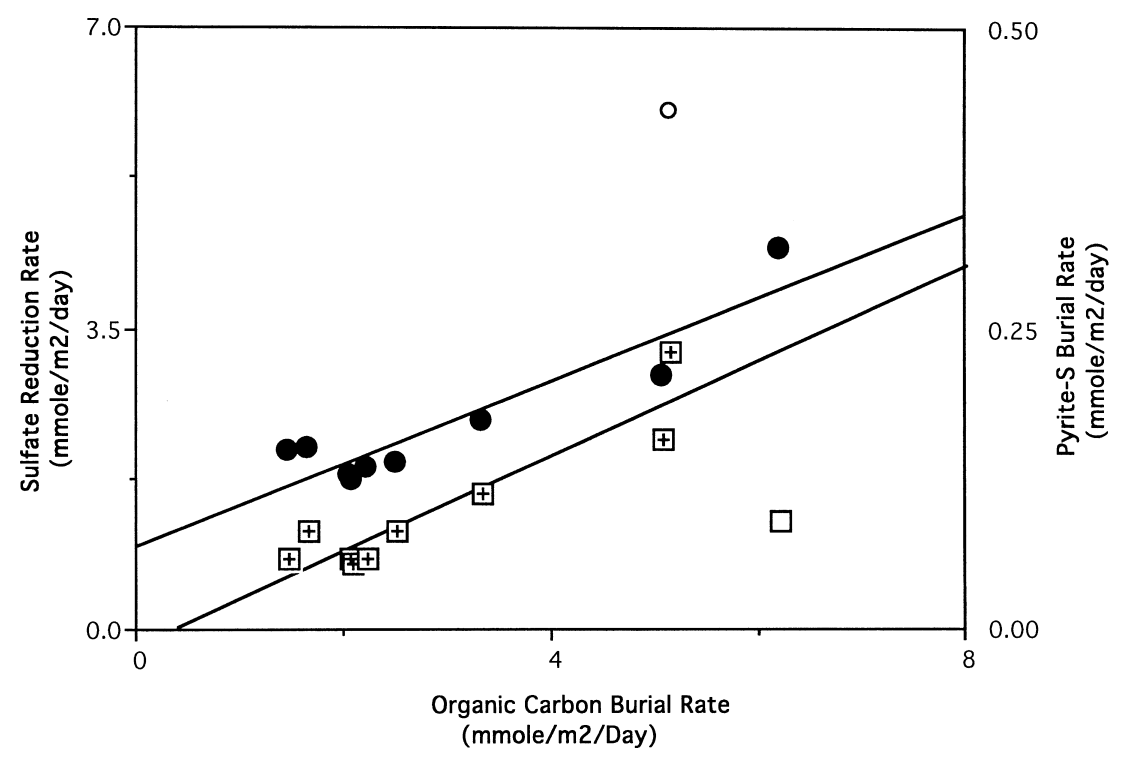

Fig. 7. Sulfate reduction rate (circles) and pyrite sulfur burial rate (squares) increased linearly with increasing organic carbon burial rate in the East China Sea continental shelf sediments. Least square fit for sulfate reduction rate is $r^{2}: 0.850$, intercept: 0.0929 , slope: 0.486 and pyrite-S $r^{2}: 0.854$, intercept: -0.015 , slope: 0.0396.

reduction rates increased linearly with the increasing organic carbon burial rates (Fig. 7). An increase in the rate of organic carbon deposition enhanced the rate of sulfate reduction since more labile carbon could be available for the sulfate reducer. In the presence of abundant reactive iron, more pyrite was produced and later buried in the sediments. An exception was found in Station 25 (Fig. 7, open square) where pyrite-sulfur burial rate was lower than the observed relation. This is probably due to an artifact from a shorter core (Fig. 6). Hence pyrite burial, as well as sulfate reduction, depended on the organic carbon deposition.

Furthermore, the $S / C$ ratios within the range of the typical "normal marine" sediment (Berner, 1970,1982) also indicated that organic carbon was limiting the pyrite formation. The conclusion was supported by Huang and Lin (1995), who found that in the East China Sea continental shelf sediments, abundant sulfate and reactive iron were found (Huang and Lin, 1995). They showed that concentrations of the least crystalline iron mineral, ferrihydrite, and sulfate were very high and as a result, sulfate and iron are unlikely to limit the pyrite formation. Organic carbon evidently is the dominating factor in controlling pyrite formation.

Both sulfate reduction rates and pyrite burial rates showed that organic carbon is limiting the pyrite formation in the study area shelf sediments. In addition, a great percentage $(96.5 \pm 0.95 \%$, Table 1$)$ of the pyrite formed through sulfate reduction was reoxidized before its final burial, probably as a result of bioturbation and 
bioirrigation. This is similar to those in the nearshore sediments where only a small percentage of pyrite-sulfur is buried (Aller, 1980; Berner and Westrich, 1985; Chanton et al., 1987), but lower than those observed near the Mississippi River Delta where up to $26 \%$ of pyrite is preserved in the sediments (Lin and Morse, 1991). Lin and Morse (1991) also showed that the percentage of pyrite-sulfur retained in the sediments was related to the sedimentation rate.

Compared to those in the Mississippi River Delta sediments, the lower pyrite-sulfur retained in the East China Sea sediments probably reflected the fact that sedimentation rates in the region were much lower than those in the Delta. Pyrite-sulfur burial rates in the East China Sea sediments were about 10-30 times lower than those in the Mississippi River Delta sediments. Since very little pyrite-sulfur can be preserved in sediments with lower organic carbon burial rate, both the pyrite-sulfur burial rate and retention in the study region are much lower than those in the Mississippi River Delta.

\section{Conclusion}

The southern East China Sea continental shelf is characterized by a low organic carbon concentration with a relatively fast sedimentation rate. The primary factor controlling pyrite formation is the supply of organic carbon. Both sulfate reduction rate and pyrite burial rate increased linearly with increasing organic carbon accumulation rate. With increasing organic carbon burial rates, more labile organic material will be able to deliver to the sulfate reducer since the organic matter will undergo a shorter period of oxic and suboxic degradation. Consequently, more pyrite will be formed and buried in sediments with higher sedimentation rate. In addition, up to $96 \%$ of the pyrite-sulfur produced from sulfate reduction was reoxidized before its final burial.

The organic carbon utilized by sulfate reduction and by organic carbon burial is $37.7 \mathrm{gC} / \mathrm{m}^{2} / \mathrm{yr}$, representing $20.6 \pm 10.4 \%$ of the primary production rate. A significant fraction of the annual productivity appears to have been missing and not depositing into the sediments. The supply of organic carbon not only limited the rate of sulfate reduction but also the final burial of pyrite in the East China Sea continental shelf sediments.

\section{Acknowledgements}

The authors thank two anonymous reviewers for their helpful and thorough comments which have significantly improved this paper. They also thank Dr. G. Wong (Old Dominion University, U.S.) for his kind support of ${ }^{209}$ Po and Dr. C.-Y. Yang for the use of alpha-counter. Drs. K.K. Liu and W.S. Chung are acknowledged for their efforts in organizing the KEEP project. This study was supported by National Science Council, NSC-852611M002A-021K2. 


\section{References}

Aller, R.C., 1980. Diagenetic processes near the sediment water interface of Long Island Sound. I. Decomposition and Nutrient element geochemistry (S, N, P). Advances in Geophysics 22, 237-350.

Aller, R.C., Mackin, J.E., Cox Jr., R.T., 1986. Diagenesis of Fe and S in Amazon inner shelf muds: apparent dominance of Fe reduction and implications for the genesis of ironstones. Continental Shelf Research 6 , 263-289.

Bender, M.L., Heggie, D.T., 1984. Fate of organic carbon reaching the deep sea floor: a status report. Geochimica Cosmochimica Acta 48, 977-986.

Berner, R.A., 1970. Sedimentary pyrite formation. American Journal Science 268, 1-23.

Berner, R.A., 1978. Sulfate reduction and the rate of deposition of marine sediments. Earth and Planetary Science Letters 37, 492-498.

Berner, R.A., 1982. Burial of organic carbon and pyrite sulfur in the modern ocean: its geochemical and environmental significance. America Journal Science 282, 451-473.

Berner, R.A., Westrich, J.T., 1985. Bioturbation and the early diagenesis of carbon and sulfur. American Journal of Science 285, 193-206.

Canfield, D.E., 1989. Sulfate reduction and oxic respiration in marine sediments: implications for organic carbon preservation in euxinic environments. Deep Sea Research 36, 121-138.

Canfield, D.E., 1991. Sulfate reduction in deep-sea sediments. American Journal Science 291, 177-188.

Canfield, D.E., Jorgensen, B.B., Fossing, H., Clud, R., Gundersen, J., Ramsing, N.B., Thamdrup, B., Hansen, J.W., Nielsen, L.P., Hall, P.O.J., 1993. Pathways of organic carbon oxidation in three continental margin sediments. Marine Geology 113, 27-40.

Carpenter, R., Peterson, M.L., Bennett, J.T., 1982. ${ }^{210} \mathrm{~Pb}$-derived sediment accumulation and mixing rates for the Washington continental slope. Marine Geology 48, 135-164.

Chanton, J.P., Martens, C.S., Goldhaber, M.B., 1987. Biogeochemical cycling in an organic-rich coastal marine basin. 6. Sulfur mass balance, oxygen uptake and sulfide retention. Geochimica Cosmochimica Acta 57, 1187-1199.

Chen, Y.-L.L., 1992. Summer phytoplankton community structure in the Kuroshio current related upwelling northeast of Taiwan. Terrestrial, Atmospheric, Oceanic Science 3, 305-320.

Christensen, J.P., 1989. Sulfate reduction and carbon oxidation rates in continental shelf sediments, an examination of offshelf carbon transport. Continental Shelf Research 9, 223-246.

Chung, Y., Chang, W.C., 1995. ${ }^{210} \mathrm{~Pb}$ fluxes and sedimentation rates on the lower continental slope between Taiwan and the South Okinawa Trough. Continental Shelf Research 15, 149-164.

DeMaster, D.J., McKee, R.A., Nittrouer, C.A., Aian, J.-C., Cheng, G.-D., 1985. Rates of sediment accumulation and particle reworking based on radiochemical measurements from continental shelf deposits in the East China Sea. Continental Shelf Research 4, 143-158.

Folk, R.L., 1968. Petrology of Sedimentary Rocks. Hemphills, 170 pp.

Flynn, W.W., 1968. The determination of low levels of Polonium-210 in environmental materials. Analytical Chimica Acta 43, 221-227.

Goldhaber, M.B., Kaplan, I.R., 1974. The sulfur cycle. In: Goldberg, E.D. (Ed.), The Sea, Vol. 5. Wiley, New York, pp. 569-655.

Guo, Y.J., 1991. The Kuroshio. Part II. Primary productivity and phytoplankton. Oceanography Marine Biological Annual Review 29, 155-189.

Henrichs, S.M., 1992. Early diagenesis of organic matter in marine sediments: progress and perplexity. Marine Chemistry 39, 119-149.

Henrichs, S.M., Reeburgh, W.S., 1987. Anaerobic mineralization of marine sediment organic matter: rates and role of anaerobic processes in the oceanic carbon economy. Geomicrobiology Journal 5, 191-237.

Huang, K.-M., Lin, S., 1995. The carbon-sulfide-iron relationship and sulfate reduction rate in the East China Sea continental shelf sediments. Geochemical Journal 29, 301-315.

Jorgensen, B.B., 1982. Mineralization of organic matter in the sea bed-the role of sulfate reduction. Nature 296, 643-645.

Lee, T., You, C.-F., Liu, T.K., 1993. Model-dependent ${ }^{10}$ Be sedimentation rates for the Taiwan Strait and their tectonic significance. Geology 21, 423-426. 
Lin, S., Morse, J.W., 1991. Sulfate reduction and iron sulfide mineral formation in Gulf of Mexico anoxic sediments. American Journal Science 291, 55-89.

Lin, S., Liu, K.K., Chen, M.P., Chang, F.Y., 1992. Distribution of organic carbon in the KEEP area continental margin sediments. Terrestrial, Atmospheric, Oceanic Science 3, 365-378.

Lin, S., Chen, C.-M., 1996. Spatial variations of heavy metals in the East China Sea continental shelf surface sediments. Chemistry and Ecology 13, 77-91.

McKee, B.A., DeMaster, D.J., Nittrouer, C.A., 1983. Concepts of sediment deposition and accumulation applied to the continental shelf near the mouth of the Yangtze River. Geology 11, 631-633.

Narita, H., Harada, K., Tsunogai, S., 1990. Lateral transport of sediment particles in the Okinawa Trough determined by natural radionuclides. Geochemical Journal 24, 207-216.

Niino, H., Emery, K.O., 1961. Sediments of shallow portions of East China Sea and South China Sea. Geological Society of American Bulletin 72, 731-762.

Nittrouer, C.A., Sternberg, R.W., Carpenter, R., Bennett, J.T., 1979. The use of ${ }^{210} \mathrm{~Pb}$ geochronology as a sedimentological tool: application to the Washington continental shelf. Marine Geology 31, 297-316.

O’Dell, J.W., Pfaff, J.D., Gales, M.E., McKee, G.D., 1984. The determination of inorganic anions in water by ion Chromatography. Method 300.0 U.S. EPA 600/4.84.017, 5 pp.

Raiswell, R., Berner, R.A., 1985. Pyrite formation in euxinic and semi-euxinic sediments. American Journal Science 285, 710-724.

Reeburgh, W.S., 1983. Rates of biogeochemical processes in anoxic sediments. Annual Review Earth Planetary Science 11, 269-298.

Reimers, C.E., Jahnke, R.A., McCorkle, D.C., 1992. Carbon fluxes and burial rates over the continental slope and rise off of Central California with implications for the global carbon cycle. Global Biogeochemical Cycles 6, 199-224.

Shiah, F.-K., Gong, G.-C., Liu, K.-K., 1995. A preliminary survey on primary productivity measured by the 14C assimilation method in the KEEP area. Acta Oceanographica Taiwanica 34, 1-15.

Shokes, R.K., 1976. Rate dependent distributions of Lead-210 and interstitial sulfate in sediments of the Mississippi River Delta. Ph.D. Thesis, Texas A and M University, 122 pp.

Smith, J.D., Hamilton, T.F., 1984. Improved technique for recovery and measurement of polonium-210 from environmental materials. Analytica Chimica Acta 160, 69-77.

Toth, D.J., Lerman, A., 1977. Organic matter reactivity and sedimentation rates in the ocean. American Journal Science 277, 265-285.

Westrich, J.T., Berner, R.A., 1984. The role of sedimentary organic matter in bacterial sulfate reduction: the G model tested. Limnology and Oceanography 29, 236-249. 